\title{
Prophylactic versus Selective Use of Surfactant in Preventing Morbidity and Mortality in Preterm Infants
}

\section{Cochrane Abstract}

Background: Surfactant therapy is effective in improving the outcome of very preterm infants. Trials have studied a wide variety of surfactant preparations used either to prevent or treat respiratory distress syndrome (RDS). In animal models, prophylactic surfactant leads to more homogeneous distribution and less evidence of lung damage. However, administration requires intubation and treatment of infants who will not go on to develop RDS. This is of particular concern with the advent of improved approaches to providing continuous distending pressure, particularly in the form of nasal continuous positive airway pressure (CPAP). Objectives: To compare the effect of prophylactic surfactant administration to surfactant treatment of established RDS in very preterm infants at risk of RDS. Search Methods: We updated the search of the Cochrane Central Register of Controlled Trials (The Cochrane Library), MEDLINE, EMBASE, CINAHL, and clinical trials.gov register on December 13, 2011. Selection Criteria: Randomized and quasi-randomized controlled trials that compared the effects of prophylactic surfactant administration to surfactant treatment of established RDS in preterm infants at risk of RDS. Data Collection and Analysis: Data regarding clinical outcomes were extracted from the reports of the clinical trials by the reviewers.
Data analysis was done in accordance with the standards of the Cochrane Neonatal Review Group. Main Results: Eleven studies were identified that met inclusion criteria [nine without routine application of CPAP in the selective treatment group; two with routine application of CPAP in the selective treatment group]. The meta-analysis of studies conducted prior to the routine application of CPAP demonstrated a decrease in the risk of air leak and neonatal mortality associated with prophylactic administration of surfactant. However, the analyses of studies that allowed for routine stabilization on CPAP demonstrated a decrease in the risk of chronic lung disease or death in infants stabilized on CPAP. When all studies were evaluated together, the benefits of prophylactic surfactant could no longer be demonstrated (see fig. 1).

\section{Reviewers' Conclusions}

Although the early trials of prophylactic surfactant administration to infants judged to be at risk of developing RDS compared to selective use of surfactant in infants with established RDS demonstrated a decreased risk of air leak and mortality, recent large trials that reflect current practice (including greater utilization of maternal steroids and routine post-delivery stabilization on (PAP) do not support these

\section{KARGER}

Fax +4161306 1234 E-Mail karger@karger.ch www.karger.com
(C) 2012 S. Karger AG, Basel

$1661-7800 / 12 / 1023-0169 \$ 38.00 / 0$

Accessible online at:

www.karger.com/neo 
differences and demonstrate less risk of chronic lung disease or death when using early stabilization on CPAP with selective surfactant administration to infants requiring intubation.
Rojas-Reyes MX, Morley CJ, Soll R: Prophylactic versus selective use of surfactant in preventing morbidity and mortality in preterm infants. Cochrane Database of Systematic Reviews 2012, Issue 3. Art. No.: CD000510. DOI: 10.1002/14651858.CD000510.pub2.

\begin{tabular}{|c|c|c|c|c|c|c|c|c|c|c|}
\hline \multirow{2}{*}{$\begin{array}{l}\text { Study } \\
\text { or subgroup }\end{array}$} & \multicolumn{2}{|c|}{ Prophylactic } & \multicolumn{2}{|c|}{ Selective } & \multirow{2}{*}{$\begin{array}{l}\text { Weight } \\
\%\end{array}$} & \multirow{2}{*}{$\begin{array}{l}\text { Risk ratio } \\
\mathrm{M}-\mathrm{H} \text {, fixed }(95 \% \mathrm{Cl})\end{array}$} & \multirow{2}{*}{\multicolumn{4}{|c|}{$\begin{array}{l}\text { Risk ratio } \\
\mathrm{M}-\mathrm{H} \text {, fixed, } 95 \% \mathrm{Cl}\end{array}$}} \\
\hline & events & total & events & total & & & & & & \\
\hline \multicolumn{11}{|c|}{ 1.1.1 Studies without routine application of CPAP } \\
\hline Bevilacqua, 1996 & 28 & 136 & 46 & 132 & 16.9 & $0.59(0.39,0.89)$ & & $\longrightarrow$ & & \\
\hline Bevilacqua, 1997 & 9 & 49 & 9 & 44 & 3.4 & $0.90(0.39,2.06)$ & & & & \\
\hline Dunn, 1991 & 9 & 62 & 8 & 60 & 3.0 & $1.09(0.45,2.63)$ & & & & \\
\hline Egberts, 1993 & 8 & 75 & 14 & 72 & 5.2 & $0.55(0.24,1.23)$ & &. & - & \\
\hline Kattwinkel, 1993 & 3 & 627 & 11 & 621 & 4.0 & $0.27(0.08,0.96)$ & & & & \\
\hline Kendig, 1991 & 23 & 235 & 40 & 244 & 14.2 & $0.60(0.37,0.97)$ & & & & \\
\hline Merritt, 1991 & 27 & 76 & 21 & 72 & 7.8 & $1.22(0.76,1.95)$ & & - & & \\
\hline Walti, 1995 & 15 & 134 & 23 & 122 & 8.7 & $0.59(0.33,1.08)$ & & 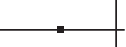 & & \\
\hline Subtotal $(95 \% \mathrm{Cl})$ & & 1,394 & & 1,367 & 63.3 & $0.69(0.56,0.85)$ & & & & \\
\hline Total events & 122 & & 172 & & & & & & & \\
\hline \multirow{2}{*}{\multicolumn{11}{|c|}{$\begin{array}{l}\text { Heterogeneity: } \chi^{2}=10.60, \text { d.f. }=7(p=0.16), I^{2}=34 \% \\
\text { Test for overall effect: } Z=3.54(p=0.0004)\end{array}$}} \\
\hline & & & & & & & & & & \\
\hline \multicolumn{11}{|c|}{ 1.1.2 Studies with routine application of CPAP } \\
\hline Dunn, 2011 & 10 & 209 & 8 & 221 & 2.8 & $1.32(0.53,3.28)$ & & & 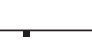 & \\
\hline SUPPORT, 2010 & 114 & 653 & 94 & 663 & 33.8 & $1.23(0.96,1.58)$ & & & $\mathbf{E}$ & \\
\hline Subtotal $(95 \% \mathrm{Cl})$ & & 862 & & 884 & 36.7 & $1.24(0.97,1.58)$ & & & & \\
\hline Total events & 124 & & 102 & & & & & & & \\
\hline \multicolumn{11}{|c|}{ Heterogeneity: $\chi^{2}=0.02$, d.f. $=1(p=0.88), 1^{2}=0 \%$} \\
\hline \multicolumn{11}{|c|}{ Test for overall effect: $Z=1.73(p=0.08)$} \\
\hline Total $(95 \% \mathrm{Cl})$ & & 2,256 & & 2,251 & 100.0 & $0.89(0.76,1.04)$ & & & & \\
\hline Total events & 246 & & 274 & & & & & & & \\
\hline \multicolumn{11}{|c|}{ Heterogeneity: $\chi^{2}=22.17$, d.f. $=9(p=0.008), 1^{2}=59 \%$} \\
\hline \multicolumn{7}{|c|}{ Test for overall effect: $Z=1.48(p=0.14)$} & $0.1 \quad 0.2$ & 0.5 & 2 & 510 \\
\hline \multicolumn{7}{|c|}{ Test for subgroup differences: $\chi^{2}=13.11$, d.f. $=1(p=0.0003), I^{2}=92.4 \%$} & Favours prop & hylactic & Favo & selective \\
\hline
\end{tabular}

Fig. 1. Effect of prophylactic versus selective use of surfactant on neonatal mortality (including subgroup analysis of studies in which infants in the selective treatment group were treated or not treated with routine application of nasal CPAP). 


\section{Commentary}

Roger F. Soll, Burlington, Vt.

Things change. In the original systematic review of 'Prophylactic surfactant versus selective use of surfactant', nine trials were included. These trials were all done in the 1990s prior to the routine use of antenatal steroids and our attempts to routinely support infants on continuous distending pressure to maintain their functional residual capacity. Throughout the past decade, the use of antenatal steroids has more than tripled and more and more investigators are becoming comfortable with the early application of distending pressure to maintain functional residual capacity. In this context, there have been several trials looking at early stabilization on distending pressure compared to a more aggressive early surfactant therapy. Certain trials approached all infants at risk of RDS while others $[1,2]$ only evaluated infants who did not require intubation in the delivery room or looked well enough not to be placed on any respiratory support.

The updated analysis of Rojas-Reyes and colleagues includes the two trials from the NICHD network (SUPPORT) [3] and the Vermont Oxford Network Delivery Room Management Study [4]. When these two studies that were conducted in the recent clinical context (with increased exposure to antenatal steroids and routine application of nasal CPAP to the control group) are included, no differences in important clinical outcomes emerge. In fact, when these two studies are combined with the nine studies from the 1990s, there are no longer clinically significant effects seen with prophylactic surfactant. When the two studies are evaluated on their own, there is a strong trend towards clinical improvement, specifically a reduction in the risk of BPD or death.
The day for routine aggressive prophylactic surfactant to all infants at risk of RDS has passed. Early stabilization with non-invasive modalities has taken its place. Selective use of surfactant, whether by intubation or other minimally invasive techniques, such as catheter insertion, will come to the fore. Further trials will be needed for us to understand specific issues regarding patient selection (e.g., steroid exposure vs. non-exposure) and the best techniques to administer surfactant in those infants who develop progressive respiratory distress.

\section{Acknowledgment}

Editorial support of the Cochrane Neonatal Review Group has been funded with Federal Funds from the Eunice Kennedy Shriver National Institute of Child Health and Human Development, National Institutes of Health, Department of Health, USA, under Contract No. HHSN275201100016C.

\section{References}

1 Morley CJ, Davis PG, Doyle LW, Brion LP, Hascoet JM, Carlin JB, COIN Trial Investigators: Nasal CPAP or intubation at birth for very preterm infants. N Engl J Med 2008;358:700-708.

-2 Sandri F, Plavka R, Ancora G, Simeoni U, Stranak Z, Martinelli S, Mosca F, Nona J, Thomson M, Verder H, Fabbri L, Halliday H, CURPAP Study Group: Prophylactic or early selective surfactant combined with nCPAP in very preterm infants. Pediatrics 2010;125:e1402-e1409.

3 SUPPORT Study Group of the Eunice Kennedy Shriver NICHD Neonatal Research Network, Finer NN, Carlo WA, Walsh MC, Rich W, Gantz MG, Laptook AR, Yoder BA, Faix RG, Das A, Poole WK, Donovan EF, Newman NS, Ambalavanan N, Frantz ID 3rd, Buchter S, Sánchez PJ, Kennedy KA, Laroia N, Poindexter BB, Cotten CM, Van Meurs KP, Duara S, Narendran V, Sood BG, O’Shea TM, Bell EF, Bhandari V, Watterberg KL, Higgins RD: Early CPAP versus surfactant in extremely preterm infants. N Engl J Med 2010;362:1970-1979.

4 Dunn MS, Kaempf J, de Klerk A, de Klerk R, Reilly M, Howard D, Ferrelli K, O'Conor J, Soll RF, Vermont Oxford Network DRM Study Group: Randomized trial comparing 3 approaches to the initial respiratory management of preterm neonates. Pediatrics 2011;128:e1069-e1076. 